\title{
Endoscopic Treatment of Subepithelial Tumors
}

\author{
Su Young Kim and Kyoung-Oh Kim \\ Division of Gastroenterology, Department of Internal Medicine, Gachon University Gil Medical Center, Incheon, Korea
}

Gastrointestinal subepithelial tumors (SETs) are generally found during endoscopy and their incidence has gradually increased. Although the indications for the endoscopic treatment of patients with SETs remain to be established, the feasibility and safety of endoscopic dissection, including the advantages of this method compared with surgical treatment, have been validated in many studies. The development of endoscopic techniques, such as endoscopic submucosal dissection, endoscopic enucleation, endoscopic excavation, endoscopic submucosal tunnel dissection, submucosal tunnel endoscopic resection, and endoscopic full-thickness resection has enabled the removal of SETs while reducing the occurrence of complications. Here, we discuss the endoscopic treatment of patients with SETs, outcomes for endoscopic treatment, and procedure-related complications. We also consider the advantages and disadvantages of the various endoscopic techniques. Clin Endosc 2018;51:19-27

Key Words: Endoscopic resection; Gastrointestinal tract; Subepithelial tumor

\section{INTRODUCTION}

Subepithelial tumors (SETs) in the gastrointestinal tract were previously treated exclusively using surgical resection. ${ }^{1}$ However, SETs with the ingrowth type are difficult to surgically remove, because it does not allow for the visualization of the gastrointestinal tract lumen. In addition, surgical resection may result in gastrointestinal deformation, impaired function due to excessive tissue removal, and other complications. Following technical advances in endoscopic treatment, the endoscopic dissection of gastrointestinal SETs was proposed. ${ }^{2-6}$ Novel endoscopy devices have allowed better dissection control, opening up a new horizon for the endoscopic treatment of patients with gastrointestinal SETs. ${ }^{6,7}$ Conventional and modified endoscopic submucosal dissections (ESDs) are effec-

Received: January 2, 2018 Revised: January 12, 2018

Accepted: January 15, 2018

Correspondence: Kyoung-Oh Kim

Division of Gastroenterology, Department of Internal Medicine, Gachon University, Gil Medical Center, 21 Namdong-daero 774 beon-gil, Namdong-gu, Incheon 21565, Korea

Tel: +82-32-460-3778, Fax: +82-32-460-3408, E-mail: kkoimge@naver.com

cc This is an Open Access article distributed under the terms of the Creative Commons Attribution Non-Commercial License (http://creativecommons.org/ licenses/by-nc/3.0) which permits unrestricted non-commercial use, distribution, and reproduction in any medium, provided the original work is properly cited. tive and safe methods that allow tissue resection for the treatment of lesions in the subepithelial layers of the gastrointestinal tissue. Excellent results have also been reported in patients with gastrointestinal SETs, including those originating from the muscularis propria (MP) layer using endoscopic tunneling techniques and endoscopic full-thickness resection (EFTR). ${ }^{6.8}$ In this brief review, we discuss the current techniques used in the endoscopic treatment of patients with gastrointestinal SETs.

\section{ENDOSCOPIC MUCOSAL RESECTION}

The small sized SETs ( 1 to $2 \mathrm{~cm}$ ) can be resected with endoscopic mucosal resection (EMR) using snare. This method, like standard snare polypectomy, places the snare under the SET and resects it with electrocautery. Before resection, it is necessary to confirm whether the tumor can move without being fixed. This method is mainly used for resecting tumors originating in the muscularis mucosa or submucosa. ${ }^{9-11}$ Endoscopic submucosal resection with a ligating device (ESMR-L) is a method in which tumor is aspirated into the ligation device and band to deploy the lesion. Then, snare resection is performed under the band. Lee et al. showed that ESMR-L was successfully performed in all patients with esophageal SETs 
without perforation. ${ }^{12}$ However, complete resection of SETs larger than $1 \mathrm{~cm}$ in diameter is very difficult, since the diameter of the ligation device is limited to $1 \mathrm{~cm}$. The transparent cap is also a tool that can be used for EMR. ESMR with a transparent cap is performed as follows. The cap is attached to the tip of endoscopy and a snare is positioned within the cap. After endoscopic suction of the lesion into the cap, the lesion is removed using prepositioned snare. ${ }^{13}$ These EMR and modified EMR are relatively easy and safe, however it is difficult to remove larger sized SETs $(>2 \mathrm{~cm})$ or those originating from the MP layer.

\section{ENDOSCOPIC SUBMUCOSAL DISSECTION}

ESD is well established as an effective treatment for gastric adenoma and early gastric cancer. ${ }^{14}$ Recently, the application of ESD for the treatment of SETs has been extended beyond mucosal lesions of the gastrointestinal tract (Table 1, Fig. 1)., Lee et al. reported the feasibility of the removal of SETs from the MP layer and a complete success rate of $75 \%$ in patients treated with ESD. ${ }^{15}$ None of the patients in that study had severe complications including perforation or massive hemorrhage. In another study, researchers demonstrated that ESD was an effective and safe method for removing gastric SETs; the overall rate of $\mathrm{R} 0$ resection was $81.1 \%$ and none of the patients had disease recurrence. ${ }^{4}$ Notably, the success rate for R0 resection was influenced by the site of tumor origin. In particular, the R0 resection rate was $100 \%$ for tumors in the submucosa layer and $68.2 \%$ for those in the MP layer. In these cases, endoscopic ultrasonography may contribute to the achievement of complete SET resection. ${ }^{4}$ Chun et al. identified the appropriate indications for ESD for the treatment of patients with gastric SETs originating from the MP layer. ${ }^{2}$ The complete resection rate in their series of patients was $74.3 \%$, and tumor size $<20 \mathrm{~mm}$ and a positive rolling sign were significantly linked to complete resection. In addition, fixed tumor mobility was significantly associated with perforation, because a tumor with less mobility has a more extensive muscular connection, and is thus difficult to remove from adjoining muscle tissue. ${ }^{2}$ Despite its efficacy and safety, ESD may not be appropriate for SETs originating in the MP layer, as evidenced by the inconsistent complete resection rates and the relatively high (up to $15 \%$ ) risk for perforation. ${ }^{2-4}$ Therefore, other types of endoscopic dissection are needed to treat these tumors.

Modified ESD techniques have recently been introduced, such as endoscopic excavation (Table 1). In this method, the mucosa overlying the lesion is cut, rather than making a circumferential incision. The SET is then dissected from the submucosal or MP layer before the incision site is closed with endoscopic clips (Fig. 2) ${ }^{16,17}$ With this technique, gastric and esophageal SETs were almost completely (96.8\%) removed, but the perforation rate was also high (12.9\%). ${ }^{16}$ Endoscopic excavation has been widely used in patients with esophageal SETs. It was successfully performed in small esophageal SETs originating from the MP layer (95.6\%). ${ }^{17}$ Although procedure-related perforation occurred in $8.9 \%$ of the patients in that study, recovery was achieved in all of the cases with conservative management. Another study demonstrated the feasibility of endoscopic enucleation in the MP layer of patients with gastric SETs. ${ }^{18}$ An insulated-tip knife and snare were used in the elimination of these tumors and the rate of successful resection was high (92.3\%), but so was the perforation rate (12.3\%). The investigators also analyzed factors that may cause perforation in endoscopic dissection. All of the perforations arose in gastrointestinal stromal tumors (GISTs) and schwannomas, because they are tightly attached to the surrounding tissue and have an incomplete tumor capsule. Another important factor was tumor location. The most common site of perforation was the fundus, and the perforation rate was significantly higher than that of other sites $(p<0.001)$. This can be attributed to the thin gastric wall of the fundus and the relatively difficult endoscopic approach, compared with that needed for SETs in other locations. Chu et al. showed that the modified ESD with enucleation was effective in patients with gastric SETs $>2 \mathrm{~cm}$ in diameter. ${ }^{19}$ Moreover, endoscopic dissection was possible even for large SETs, which were otherwise treated surgically. Nonetheless, despite the advantages of ESD and modified ESD methods, the limitations include the relatively high rate of procedure-related complications (particularly, perforation) and the inability to achieve complete resection in some cases. Furthermore, given the short follow-up duration of the abovementioned studies, SETs suspected of being malignant should continue to be treated surgically rather than via endoscopic dissection.

\section{ENDOSCOPIC SUBMUCOSAL TUNNELING}

Peroral endoscopic myotomy (POEM), which was developed by Inoue et al., is currently the standard of care in patients with achalasia. ${ }^{20}$ The POEM technique creates a submucosal tunnel enabling endoscopic procedures under the mucosal layer as well as the treatment of the MP layer lesions with only a low risk for contamination and leakage after closure. Submucosal tunneling has been applied to the endoscopic dissection of gastrointestinal SETs, a procedure referred to as endoscopic submucosal tunnel dissection (ESTD) or sub- 


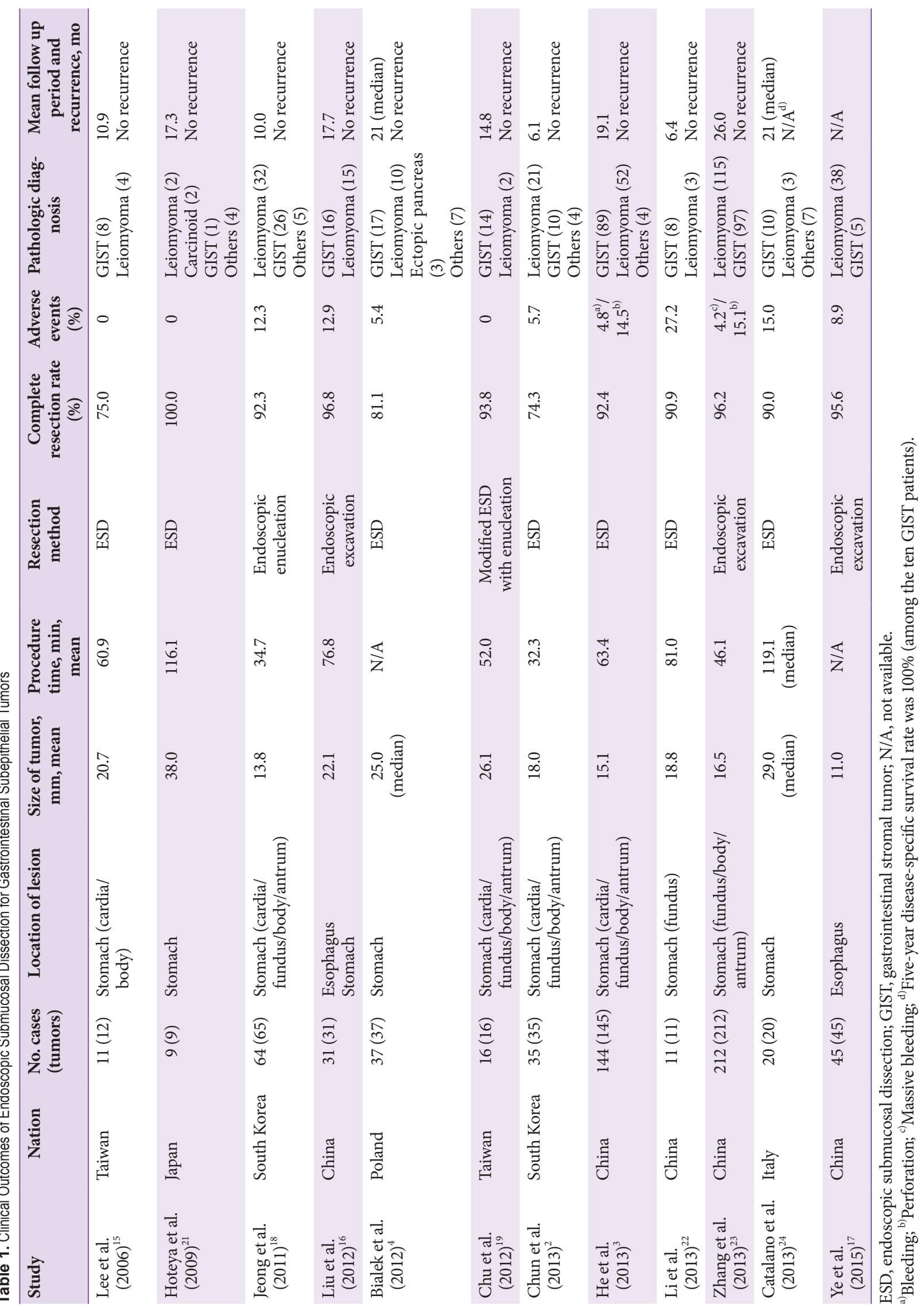


mucosal tunnel endoscopic resection (STER) (Table 2)..$^{25-27}$ Benefits include the retention of an intact mucosal layer, fast wound healing, and avoidance of the leakage of bowel material. Inoue et al. performed a submucosal endoscopic tumor resection that included the creation of a submucosal tunnel. ${ }^{25}$ The key steps of the procedure are: making a mucosal incision proximal to the SET, creating the submucosal tunnel, dissecting the tumor from the overlying mucosal/submucosal and muscular layers under direct endoscopic viewing, and endoscopic hemostasis followed by closure of the mucosal incision using endoscopic clips. In that study, all of the SETs in the esophagus and cardia were resected completely and no complications occurred. ${ }^{25}$ Gong et al. also showed the feasibility of ESTD in patients with upper gastrointestinal SETs. ${ }^{26}$ All of the tumors were located in the esophagus and cardia, and $83.3 \%$ were removed by en bloc resection. In a prospective large study of STER in patients with SETs, the procedure was successful in all cases (100\%) and no residual or recurrent tumors were detected. ${ }^{27}$ The complication rate was $9.4 \%$, and all of the complications were successfully treated using conserva- tive management. GISTs and tumors originating deeper in the MP layer were risk factors for postoperative complications. Endoscopic dissection is more difficult for SETs located in the esophagogastric junction than in other locations, because the narrow space and esophageal peristalsis interfere with detailed endoscopic control. Nonetheless, a complete resection rate of $100 \%$ in patients with SETs at the esophagogastric junction was reported. ${ }^{28}$ None patients had disease recurrence or procedure-related esophageal stricture during follow-up. Compared with studies on submucosal tunneling techniques in patients with esophageal SETs, the utility of this approach in gastric SETs has been less well examined. In their study, Li et al. examined the clinical effects of STER in patients with gastric SETs, ${ }^{29}$ and reported a complete resection rate of $100 \%$ and all of the adverse events could be managed conservatively. In addition, a recent report evaluated the long-term outcome of STER in patients with upper gastrointestinal SETs. ${ }^{30}$ The 180 patients who underwent STER were free from disease recurrence during a median follow-up of 36 months. Despite these successes, the limitations of ESTD and STER must be
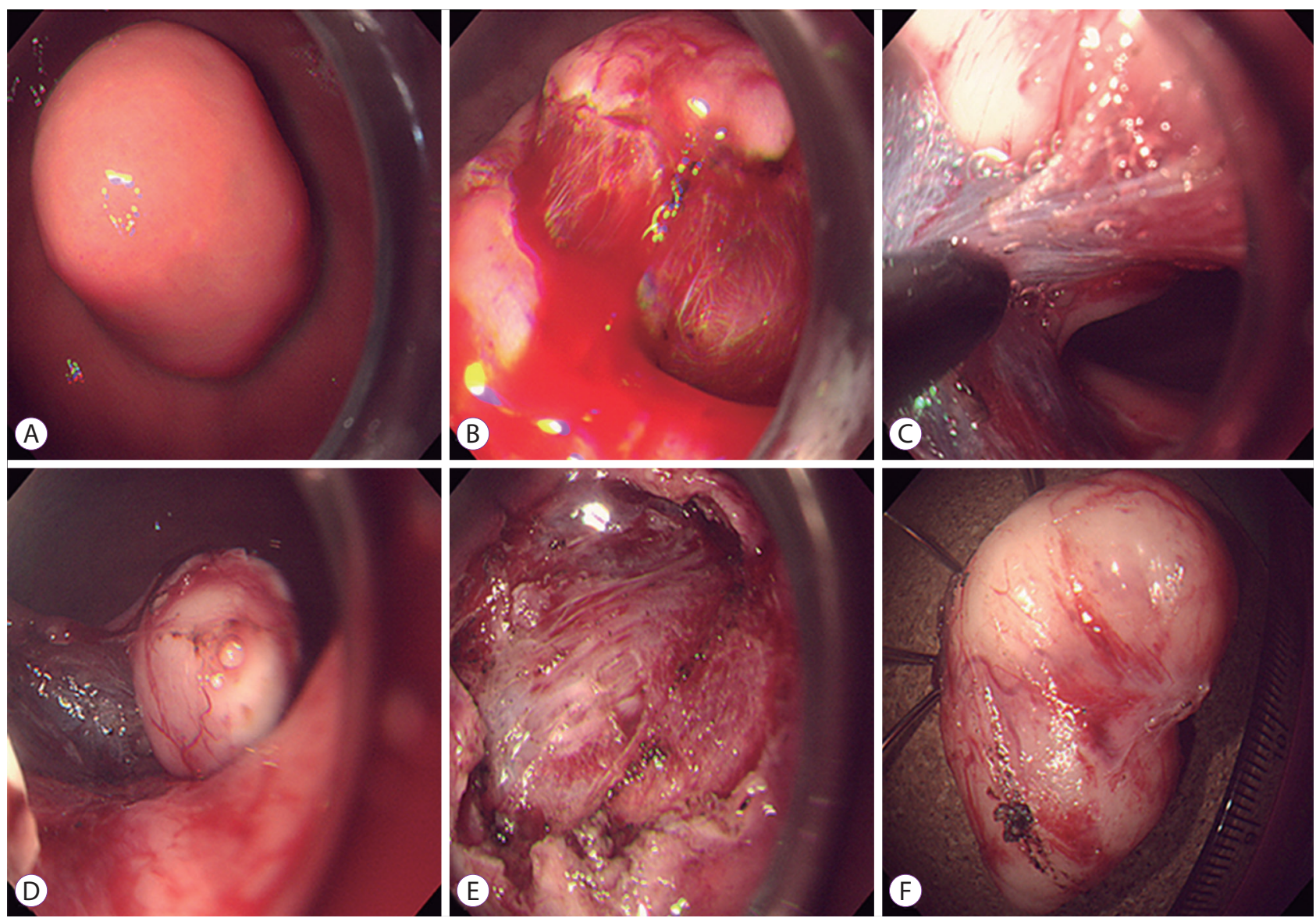

Fig. 1. Endoscopic submucosal dissection of a gastrointestinal stromal tumor. (A) A large subepithelial tumor is observed at the high body of the stomach. (B, C) Circumferential incision and submucosal dissection of the tumor is performed. (D) Most of the subepithelial tumor is exposed to the lumen. (E) A post-endoscopic submucosal dissection ulcer is observed. (F) The resected specimen (tumor size is $2.4 \mathrm{~cm}$ ). 
kept in mind, particularly their difficult use in tumors located in the fundus and proximal corpus, because of the difficulty tunnel creation, the considerably thick gastric mucosa, and the complicated removal of SETs $>4 \mathrm{~cm}$ in diameter.

\section{ENDOSCOPIC FULL-THICKNESS RESECTION WITHOUT LAPAROSCOPY}

EFTR is the preferred treatment option for patients with gastrointestinal SETs originating from the deep MP layer and exhibiting predominantly extraluminal growth (Table 3 ). Zhou et al. showed that EFTR without laparoscopy was effective for the removal of gastric SETs originating from the MP layer. ${ }^{31}$ The EFTR procedure is as follows: after precutting, a circumferential incision is made in the MP layer around the tumor; an incision is then made in the serosal layer around the tumor; full-thickness resection of the tumor, including the serosal layer, is performed; and the perforated gastric wall is sutured using endoscopy clips. The mean tumor size was $28 \mathrm{~mm}$ and the complete resection rate was $100 \%$. There were no major complications and no recurrences during the mean follow-up. Another study also demonstrated the feasibility of EFTR for gastric SETs arising from the MP layer. ${ }^{32} \mathrm{~A}$ complete resection rate of $98 \%$ was achieved and none of the patients had severe adverse events. The use of clip closure and Endoloop ligature (additional closure devices) may have contributed to the prevention of gastric perforation. New suturing devices have also been used to correct the perforations that may occur during EFTR. Schmidt et al. recommended the use of these devices to place one to three full-thickness sutures underneath the tumor, after which resection is performed. ${ }^{5}$ Although perforations occurred in $9.6 \%$ of the patients treated in this manner, all were managed endoscopically. An advantage of this "suture first, cut later" method is that it can be used to treat relatively large (approximately $4 \mathrm{~cm}$ ) SETs regardless of their location in the stomach and without the need for laparoscopy. ${ }^{5}$ While EFTR is feasible for lesions of any shape and located on any side of the lumen, it should be noted that EFTR without laparoscopy assistance requires a high-quality endoscopic technique and
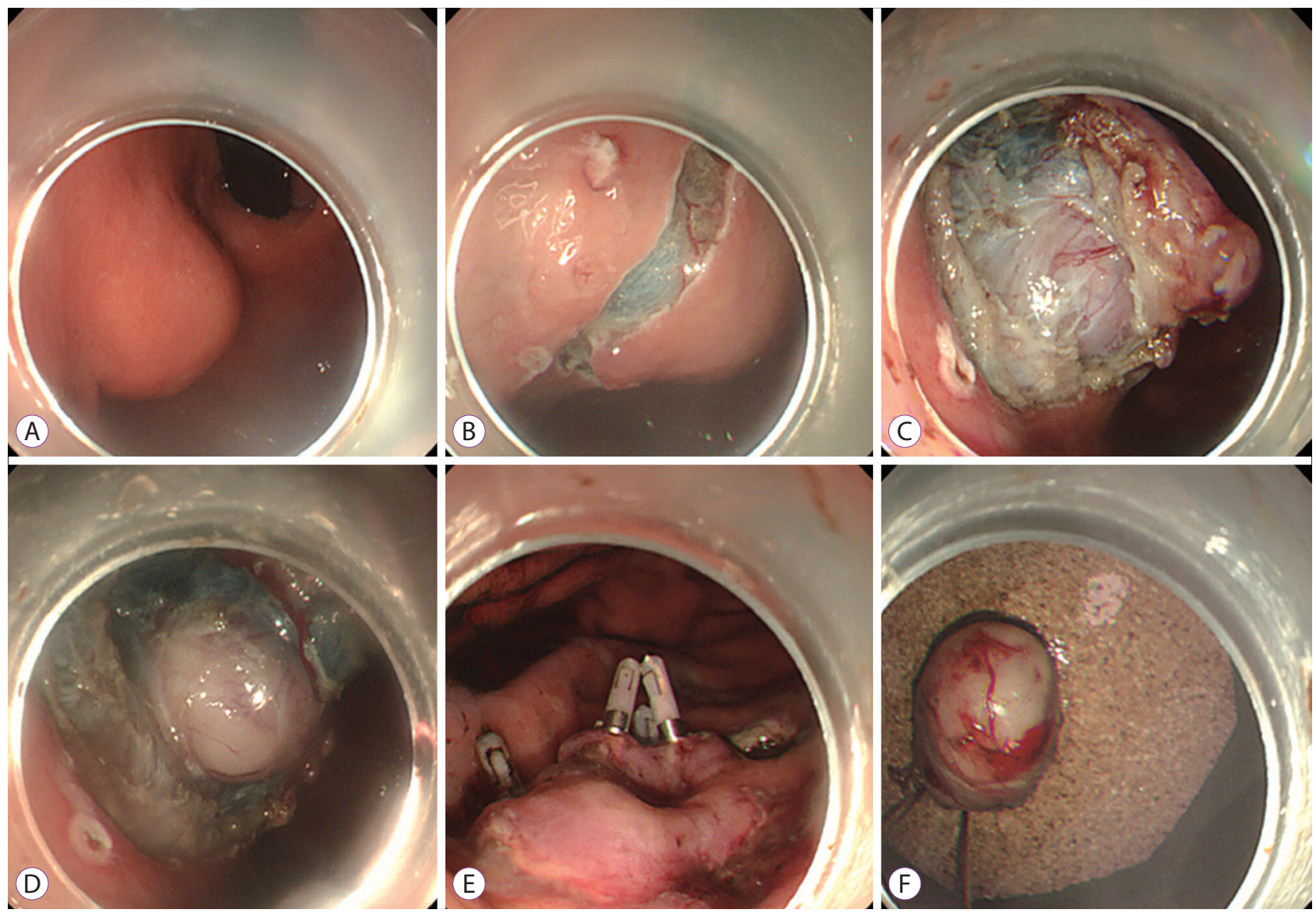

Fig. 2. Endoscopic excavation with clipping of a gastrointestinal stromal tumor. (A) A large and round subepithelial tumor is found at the high body of the stomach. (BD) After the mucosa overlying the lesion is cut, the subepithelial tumor is excavated from the muscularis propria layer. $(E)$ The wound is closed endoscopic clips. (F) The resected specimen (tumor size is $2.0 \mathrm{~cm}$ ). 
C clinical endoscopy

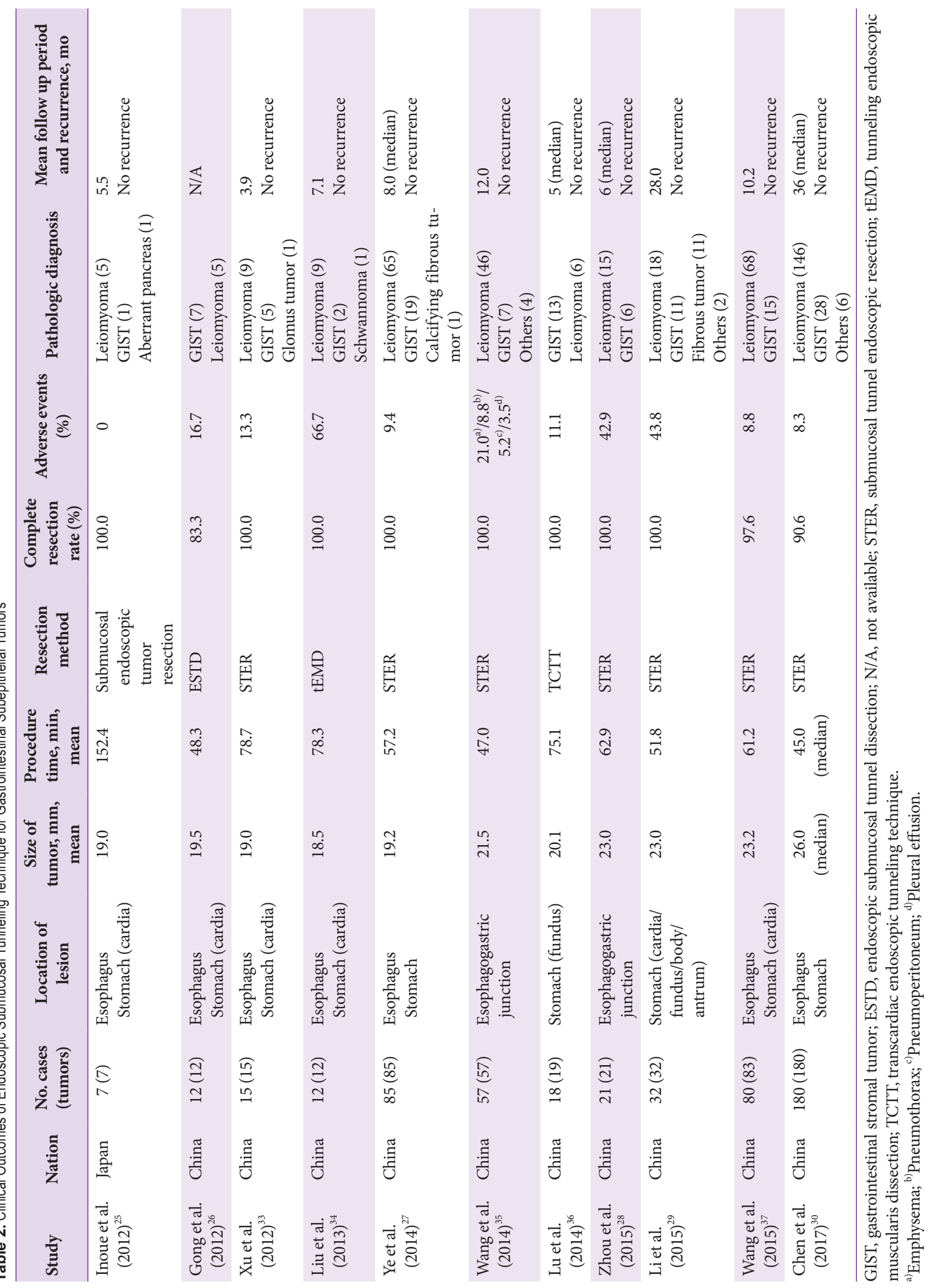




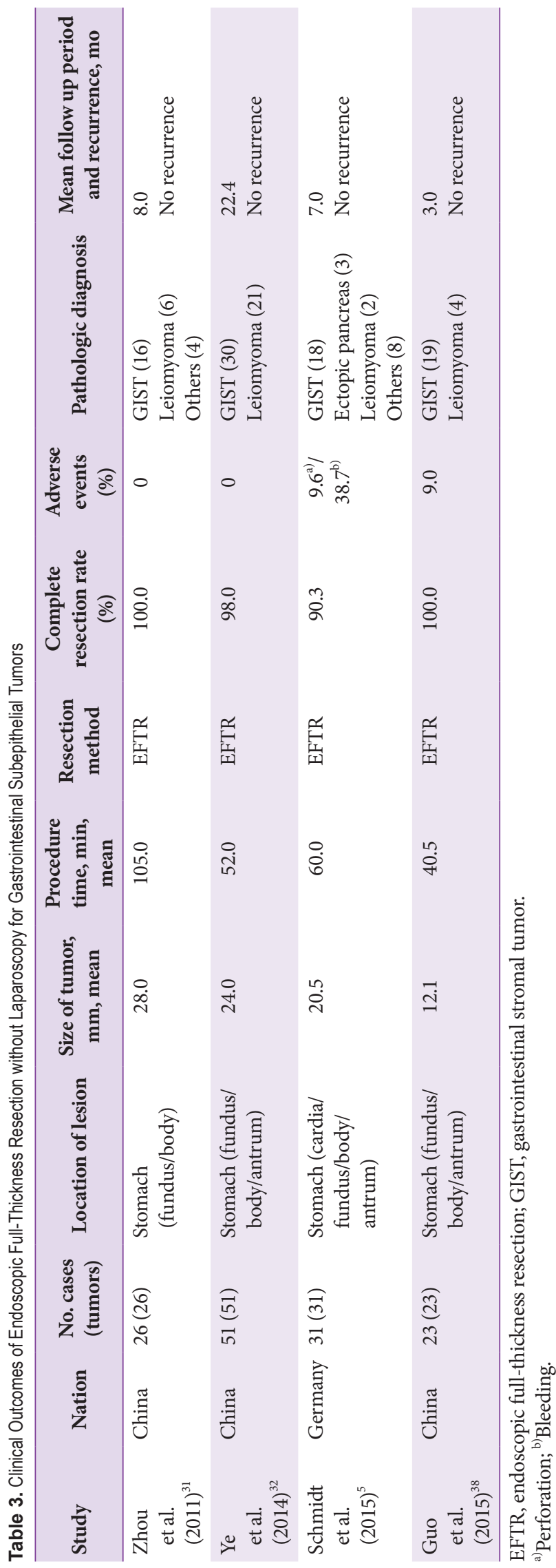

large SETs cannot be easily removed. In addition, there is a risk for intraperitoneal infection after the procedure if mucosal suturing is inadequate.

\section{ISSUES TO OVERCOME IN THE ENDOSCOPIC DISSECTION OF GASTROINTESTINAL SETS}

Several unsolved issues remain regarding the use of different endoscopic dissection techniques to treat gastrointestinal SETs. First, the clear endoscopic treatment indication for gastrointestinal SETs has yet to be determined. A very large tumor with primarily extraluminal growth or widespread involvement of the MP layer may be better treated surgically because the incidence of procedure-related complications following endoscopic dissection is relatively high and the rate of en bloc resection is low. Second, there is no optimal tumor-surveillance protocol for patients treated with endoscopic resection. Both considerations carry added weight for SETs with malignant potential. Third, the rate of complications arising from endoscopic procedures is still troublesome, particularly for SETs originating from the MP layer. Finally, the feasibility of endoscopic treatment may differ according to the location of the SET, whereas this is not a concern with surgical treatment. In particular, endoscopic approaches to SETs involving the fundus or cardia are challenging and the risks for procedural adverse events and incomplete resection are therefore relatively high.

\section{CONCLUSIONS}

Endoscopic treatment of gastrointestinal SETs is feasible, but before the role of endoscopy can be expanded, several limitations have to be addressed, particularly the currently high rate of complications, specifically perforations. Moreover, if perforation occurs, secondary complications such as emphysema and intraperitoneal infection must be prevented. Carbon dioxide insufflation and recently developed closing devices may contribute to lowering the perforation rate. While numerous studies have evaluated the efficacy of endoscopic dissection for SETs, prospective comparative studies seeking to determine the indication for endoscopic dissection versus surgery are needed, as are long-term follow-up studies to evaluate recurrence after endoscopic dissection of SETs. A hybrid approach combining endoscopy and laparoscopy may turn out to be the best method for SETs that are difficult to treat using endoscopy alone and will increase patients' satisfaction. Finally, the experience and skill of the endoscopist are obvi- 
ously important factors in achieving complete resection and minimal complications. In conclusion, endoscopic treatment is a technically feasible procedure for the treatment of patients with gastrointestinal SETs, but technical advances and additional studies are needed to improve the clinical outcome of patients with endoscopically treated SETs.

Conflicts of Interest

The authors have no financial conflicts of interest.

\section{REFERENCES}

1. Ponsaing LG, Hansen MB. Therapeutic procedures for submucosal tumors in the gastrointestinal tract. World J Gastroenterol 2007;13:33163322.

2. Chun SY, Kim KO, Park DS, et al. Endoscopic submucosal dissection as a treatment for gastric subepithelial tumors that originate from the muscularis propria layer: a preliminary analysis of appropriate indications. Surg Endosc 2013;27:3271-3279.

3. He Z, Sun C, Wang J, et al. Efficacy and safety of endoscopic submucosal dissection in treating gastric subepithelial tumors originating in the muscularis propria layer: a single-center study of 144 cases. Scand J Gastroenterol 2013;48:1466-1473.

4. Bialek A, Wiechowska-Kozłowska A, Pertkiewicz J, et al. Endoscopic submucosal dissection for treatment of gastric subepithelial tumors (with video). Gastrointest Endosc 2012;75:276-286.

5. Schmidt A, Bauder M, Riecken B, von Renteln D, Muehleisen H, Caca K. Endoscopic full-thickness resection of gastric subepithelial tumors: a single-center series. Endoscopy 2015;47:154-158.

6. Kim SY, Kim KO. Management of gastric subepithelial tumors: the role of endoscopy. World J Gastrointest Endosc 2016;8:418-424.

7. Wong VWY, Goto O, Gregersen H, Chiu PWY. Endoscopic treatment of subepithelial lesions of the gastrointestinal tract. Curr Treat Options Gastroenterol 2017;15:603-617.

8. Zhang Y, Ye LP, Mao XL. Endoscopic treatments for small gastric subepithelial tumors originating from muscularis propria layer. World J Gastroenterol 2015;21:9503-9511.

9. Yu JP, Luo HS, Wang XZ. Endoscopic treatment of submucosal lesions of the gastrointestinal tract. Endoscopy 1992;24:190-193.

10. Kojima T, Takahashi H, Parra-Blanco A, Kohsen K, Fujita R. Diagnosis of submucosal tumor of the upper GI tract by endoscopic resection. Gastrointest Endosc 1999;50:516-522.

11. Kim GH. Endoscopic resection of subepithelial tumors. Clin Endosc 2012;45:240-244

12. Lee DG, Kim GH, Park DY, et al. Endoscopic submucosal resection of esophageal subepithelial lesions using band ligation. Endoscopy 2011;43:822-825.

13. Kajiyama T, Sakai M, Torii A, et al. Endoscopic aspiration lumpectomy of esophageal leiomyomas derived from the muscularis mucosae. Am J Gastroenterol 1995;90:417-422.

14. Chung IK, Lee JH, Lee S-H, et al. Therapeutic outcomes in 1000 cases of endoscopic submucosal dissection for early gastric neoplasms: Korean ESD study group multicenter study. Gastrointest Endosc 2009;69:12281235.

15. Lee IL, Lin PY, Tung SY, Shen CH, Wei KL, Wu CS. Endoscopic submucosal dissection for the treatment of intraluminal gastric subepithelial tumors originating from the muscularis propria layer. Endoscopy 2006;38:1024-1028

16. Liu BR, Song JT, Qu B, Wen JF, Yin JB, Liu W. Endoscopic muscularis dissection for upper gastrointestinal subepithelial tumors originating from the muscularis propria. Surg Endosc 2012;26:3141-3148.
17. Ye LP, Zhu LH, Zhou XB, Mao XL, Zhang Y. Endoscopic excavation for the treatment of small esophageal subepithelial tumors originating from the muscularis propria. Hepatogastroenterology 2015;62:65-68.

18. Jeong ID, Jung SW, Bang SJ, Shin JW, Park NH, Kim DH. Endoscopic enucleation for gastric subepithelial tumors originating in the muscularis propria layer. Surg Endosc 2011;25:468-474.

19. Chu YY, Lien JM, Tsai MH, et al. Modified endoscopic submucosal dissection with enucleation for treatment of gastric subepithelial tumors originating from the muscularis propria layer. BMC Gastroenterol 2012;12:124.

20. Inoue $\mathrm{H}$, Minami $\mathrm{H}$, Kobayashi $\mathrm{Y}$, et al. Peroral endoscopic myotomy (POEM) for esophageal achalasia. Endoscopy 2010;42:265-271.

21. Hoteya S, Iizuka T, Kikuchi D, Yahagi N. Endoscopic submucosal dissection for gastric submucosal tumor, endoscopic sub-tumoral dissection. Dig Endosc 2009;21:266-269.

22. Li L, Wang F, Wu B, Wang Q, Wang C, Liu J. Endoscopic submucosal dissection of gastric fundus subepithelial tumors originating from the muscularis propria. Exp Ther Med 2013;6:391-395.

23. Zhang Y, Ye LP, Zhou XB, et al. Safety and efficacy of endoscopic excavation for gastric subepithelial tumors originating from the muscularis propria layer: results from a large study in China. J Clin Gastroenterol 2013;47:689-694.

24. Catalano F, Rodella L, Lombardo F, et al. Endoscopic submucosal dissection in the treatment of gastric submucosal tumors: results from a retrospective cohort study. Gastric Cancer 2013;16:563-570.

25. Inoue $\mathrm{H}$, Ikeda $\mathrm{H}$, Hosoya $\mathrm{T}$, et al. Submucosal endoscopic tumor resection for subepithelial tumors in the esophagus and cardia. Endoscopy 2012;44:225-230.

26. Gong W, Xiong Y, Zhi F, Liu S, Wang A, Jiang B. Preliminary experience of endoscopic submucosal tunnel dissection for upper gastrointestinal submucosal tumors. Endoscopy 2012;44:231-235.

27. Ye LP, Zhang Y, Mao XL, Zhu LH, Zhou X, Chen JY. Submucosal tunneling endoscopic resection for small upper gastrointestinal subepithelial tumors originating from the muscularis propria layer. Surg Endosc 2014;28:524-530.

28. Zhou DJ, Dai ZB, Wells MM, Yu DL, Zhang J, Zhang L. Submucosal tunneling and endoscopic resection of submucosal tumors at the esophagogastric junction. World J Gastroenterol 2015;21:578-583.

29. Li QL, Chen WF, Zhang C, et al. Clinical impact of submucosal tunneling endoscopic resection for the treatment of gastric submucosal tumors originating from the muscularis propria layer (with video). Surg Endosc 2015;29:3640-3646.

30. Chen T, Zhou PH, Chu Y, et al. Long-term outcomes of submucosal tunneling endoscopic resection for upper gastrointestinal submucosal tumors. Ann Surg 2017;265:363-369.

31. Zhou PH, Yao LQ, Qin XY, et al. Endoscopic full-thickness resection without laparoscopic assistance for gastric submucosal tumors originated from the muscularis propria. Surg Endosc 2011;25:2926-2931.

32. Ye LP, Yu Z, Mao XL, Zhu LH, Zhou XB. Endoscopic full-thickness resection with defect closure using clips and an endoloop for gastric subepithelial tumors arising from the muscularis propria. Surg Endosc 2014;28:1978-1983.

33. Xu MD, Cai MY, Zhou PH, et al. Submucosal tunneling endoscopic resection: a new technique for treating upper GI submucosal tumors originating from the muscularis propria layer (with videos). Gastrointest Endosc 2012;75:195-199.

34. Liu BR, Song JT, Kong LJ, Pei FH, Wang XH, Du YJ. Tunneling endoscopic muscularis dissection for subepithelial tumors originating from the muscularis propria of the esophagus and gastric cardia. Surg Endosc 2013;27:4354-4359.

35. Wang XY, Xu MD, Yao LQ, et al. Submucosal tunneling endoscopic resection for submucosal tumors of the esophagogastric junction originating from the muscularis propria layer: a feasibility study (with videos). Surg Endosc 2014;28:1971-1977.

36. Lu J, Zheng M, Jiao T, Wang Y, Lu X. Transcardiac tunneling technique 
for endoscopic submucosal dissection of gastric fundus tumors arising from the muscularis propria. Endoscopy 2014;46:888-892.

37. Wang H, Tan Y, Zhou Y, et al. Submucosal tunneling endoscopic resection for upper gastrointestinal submucosal tumors originating from the muscularis propria layer. Eur J Gastroenterol Hepatol 2015;27:776-780.
38. Guo J, Liu Z, Sun S, et al. Endoscopic full-thickness resection with defect closure using an over-the-scope clip for gastric subepithelial tumors originating from the muscularis propria. Surg Endosc 2015;29:33563362. 